\title{
The participation in leisure activities and the quality of life of people with psychosis in England: A multi-site cross-sectional study
}

Kayonda Hubert Ngamaba ( $\sim$ kayonda.ngamaba@york.ac.uk)

University of York, UK https://orcid.org/0000-0003-1227-7990

Martin Webber

University of York Department of Social Policy and Social Work

Penny Xanthopoulou

University of Exeter Institute of Health Research

Agnes Chevalier

Queen Mary University of London Barts and The London School of Medicine and Dentistry

Domenico Giacco

University of Warwick Warwick Medical School

\section{Research}

Keywords: Quality of life, Psychosis, Leisure activities, Mental health

Posted Date: July 26th, 2021

DOI: https://doi.org/10.21203/rs.3.rs-734144/v1

License: (c) (7) This work is licensed under a Creative Commons Attribution 4.0 International License. Read Full License 


\section{Abstract \\ Background}

Leisure activities can improve the quality of life in the general population. For people with psychosis, negative symptoms are often a barrier to engaging in leisure social activities. However, we do not know if participation in leisure activities is associated with quality of life in this group and whether psychosocial interventions should aim to increase leisure activities amongst people with psychosis.

\section{Aim}

This study aims to investigate whether participation in leisure activities is associated with better quality of life of people with psychosis in England.

\section{Methods}

A cross-sectional survey was conducted in 6 NHS community mental health trusts. Adults aged $18-65(\mathrm{~N}=533)$ with a diagnosis of psychosis-related condition (ICD-10 F20-29) were recruited from outpatient secondary mental health services. Several measures were used: Time Use Survey (TUS), Manchester Short Assessment of Quality of Life (MANSA). Descriptive statistics and multiple regression analyses were conducted.

\section{Results}

Participation in at least one leisure activity in the last 7 days was reported by the majority of participants ( $n=480,90 \%)$. The average number of weekly leisure activities they attended was $M=2.42(S E=0.06)$. Participants' quality of life increased with the number of leisure activities they attended. After controlling for socio-demographic factors, participation in leisure activities was positively associated with quality of life in people with $p s y c h o s i s(b=0.083, S E=0.035, p=$ $0.019,95 \% \mathrm{Cl}$ [0.013 to 0.153$]$ ). We found a gender difference: For Males, the association between attendance in leisure activities and quality of life is significantly positive; $b=0.132, \mathrm{SE}=0.041, \mathrm{p}=0.002,95 \% \mathrm{Cl}[0.050$ to 0.213$]$. For females: the association between attendance in leisure activities and quality of life was no significant.

\section{Conclusion}

People with psychosis who attend more leisure activities have a higher quality of life. Quality of life was higher amongst males who attended leisure activities. Intervention which helps improve participation in leisure activities may be beneficial for people with psychosis.

\section{Introduction}

Leisure activities have been associated with people's quality of life (1). Engaging in leisure activities is associated with improvements in personal relationships, self-esteem, time structure and in the creation of capital networks and employment $(2,3)$.

The government in England is promoting the quality of life of primary care patients through sport and leisure activities. For example, in 2019 , it launched a new National Academy for Social Prescribing (NASP) (see www.socialprescribingacademy.org.uk/) to give every patient in the country access to sport and leisure activities $(4,5)$. This involved different sectors such as Primary and Secondary care, Sport England, Arts Council England, Researchers and a range of voluntary sector organisations to establish a great evidence base and raise the profile of the NASP.

Previous studies have reported that participation in leisure activities can positively affect the quality of life of older people (6) and people with common mental health conditions $(3,7-9)$.

Less studies have investigated gender difference in mental health when it come to the participation in leisure activities. A 6 years panel study conducted amongst adults aged 50-59 in Japan found that the involvement in both leisure activities such as 'hobbies or cultural activities' and 'exercise or sports' were significantly and positively related to mental health status in both men and women (10). Nevertheless, in men, both 'hobbies or cultural activities' and 'exercise or sports' were significantly related to mental health status only when conducted 'with others'. In women, the effects of 'hobbies or cultural activities' on mental health status were no differences regardless of the ways of participating, while the result of 'exercise or sports' was same as that in men (10). Moreover, a prospective cohort study conducted in the western part of Denmark amongst 15-24 years old found that boys are more physically active than girls (9). However, most of these studies have investigated the link between physical leisure activities (e.g., exercise, gym and sports) and quality of life in people with common mental health conditions such as anxiety and depression $(3,7)$, in unemployed people (3), people with cancer (8), or people with poor mental health in early adulthood (9). To date, studies of social interventions which aim to improve community participation (11) have not specifically targeted leisure activities. There is no data as to whether participation in leisure activities have an effect on overall quality of life of people with psychosis.

Leisure activities refer to any un-obligated time or activity that bring direct satisfaction, a state of being content and happy following participation in specific activities performed in your own spare time without any pressure for survival $(2,6,12,13)$. This includes activities such as going out for meal or going to the cinema, for example. Participation in leisure activities could be a complex procedure for some people because it includes the processes of finding the right activity, planning and implementing appropriate and interesting leisure activities (14). 
Despite several studies suggesting that leisure activities contribute to quality of life in the general population, people with psychosis might experience problems with engaging in leisure activities due to negative symptoms. Previous studies have found that anhedonia, emotional blunting and low energy affects the motivation and ability to engage, establish and maintain social relationships $(11,15)$. Secondly, people with psychosis might experience social disadvantages such as unemployment or living alone with fewer opportunities to use social skills $(16,17)$. Thirdly, passive social withdrawal, which is a core behavioural feature in schizophrenia, is associated mainly with asociality, though it can also be seen secondary to psychotic symptoms. While one person may lack desire for affiliation, another may be isolated because of paranoid fears (18).

This study aims to investigate whether attendance in leisure activities is associated with the quality of life of people with psychosis in England. It addresses two evidence gaps. First, little is currently known about the participation in leisure activities of people with psychosis. Secondly, there have been no multi-site cross-sectional studies exploring the association of leisure activities with the quality of life of people with psychosis. The findings of this study may help to inform intervention development which may support the engagement of people with psychosis in leisure activities.

\section{Methods}

Study design and participants

A cross-sectional survey was conducted in NHS Community Mental Health Team (CMHT)s in England. CMHT is an umbrella term used to describe a multiprofessional team involved in the delivery of mental health care and it's formed of community psychiatric nurses, occupational therapists, social workers, psychologists, psychiatrists, and health care support workers.

From June 2017 to May 2018, participants were recruited in six participating NHS Trusts covering a range of geographical areas, in both urban and rural contexts: Cornwall Partnership NHS Foundation Trust; Devon Partnership NHS Trust; East London NHS Foundation Trust (covering East London, Luton and Bedfordshire); Oxford Health NHS Foundation Trust (covering large areas of Oxfordshire and Buckinghamshire), and Somerset Partnership NHS Foundation Trust; Tees, Esk and Wear Valleys NHS Foundation Trust (covering county Durham, Darlington, Teeside, York and North Yorkshire). Participants were identified by clinicians or clinical study officers from CMHTs caseloads.

Participants were eligible for inclusion if they met the following criteria:

- $\quad$ Adults aged 18-65 years old

- A clinical diagnosis of a psychotic disorder according to the International Classification of Disease-10 (ICD-10) codes F20-29, as identified in clinical records

- $\quad$ Receiving care from outpatient secondary mental health services or primary care services

- Have capacity to provide informed consent

- Able to communicate in English

Exclusion criteria:

- A current and primary diagnosis of substance use disorder (ICD-10 F10-19)

- Had been hospitalised in the previous week (although these potential participants could be re-approached at a later time)

- Their postcodes could not be obtained because they were homeless or living in temporary accommodation at the time of the survey.

Procedures and measures

Eligible participants were identified by clinicians or clinical study officers and asked for their agreement to speak to one member of the research team. Participants then completed the study questionnaires and researchers accessed participant clinical records to retrieve clinical and socio-demographic characteristics. All participants who agreed to take part in this study were interviewed in quiet rooms in community mental health teams, primary care settings, or at participant's homes using standardised case report forms. All interviews were face-to-face and took about 45 minutes to complete. Several measures were used during the assessments:

First, the Time Use Survey (TUS) (19) explored whether participants engaged in leisure activities in the past week and for more than 10 minutes in each activity. It included activities such as going out for a meal, going to the cinema, museum, library, day centre, going to the gym, outdoor trips or attending a religious group/activity. We also collected data on whether participants attended sports activities in the last 7 days.

Second, participants reported satisfaction with quality and quantity of friendships, financial situation and accommodation measured using the sixteen items of the Manchester Short Assessment of Quality of Life (MANSA), which was rated on a score from 1 (very dissatisfied) to 7 (very satisfied). For example, researchers asked questions such as: How satisfied are you with: your life as a whole today; being unemployed; financial situation; your friendships; your leisure activities; your accommodation; your personal safety; people that you live with; your sex life; your physical health and your mental health.

MANSA has been widely used to assess the quality of life of people with psychosis and its psychometric properties have been well established (20-22). 
Researchers collected additional participant characteristics such as age, gender (male/female), marital status (single/in a relationship), country of birth (born in the United Kingdom/born in a different country), education level (primary/secondary/further), living situation (living alone/living with someone), accommodation (living independently/living in supported accommodation), employment (employed/not employed), receipt of welfare benefits (or not), and length of illness (calculated in number of years from the day of first contact with mental health services). These were collected from participants assessments and checked against available data in medical records.

Description of the Sample

A sample of 548 participants completed the study, of whom 535 (97.6\%) reported their participation in leisure activities during the previous week. 407 (74.3\%) participants responded to all 16 questions related to the quality of life MANSA measure. The number of people who responded to MANSA questions was different from one question to another; for example: 527 responded to "how satisfied they were with their life as a whole"; 521 to "financial situation"; 429 to "sex life", 523 to "mental health". Due to missing data and given that many explanatory variables were used in the multivariate model, the number of respondents decreased from 535 to 396 .

Ethics Committee Approval

The West Midlands - Solihull Research Ethics Committee (17/WM/0191) approved the study, protocol, and informed consent forms. All participants were given the information sheet about the survey and written informed consent was obtained from all participants.

Statistical analysis

Descriptive statistics (i.e., Mean and Standard Deviation) are reported for quality of life, leisure activities, sport activities and social contacts. We report the mean, standard error, and $95 \%$ confidence interval of quality of life of participants when they (a) did not attend any leisure activities, (b) attended at least one leisure activity.

Linear regression analysis tested associations between quality of life and attendance in leisure activities. First, we used univariable tests to explore the associations between individual participant-level variables and the dependent variable. Second, each significant association at an alpha level of $10 \%$ in these univariable tests was entered in a final multivariable model, set at a significance level of $5 \%$. In the regression analysis, quality of life was set as the outcome variable and attendance in leisure activities as independent variables. We controlled for socio-demographic factors and for sports activities as participants were asked (alongside leisure activities) to report their participation in fitness activities during the previous week.

We reported odds ratios (OR) with their corresponding $95 \%$ confidence intervals ( $\mathrm{Cl}$ ). All statistical analyses were conducted using Stata 16.0 software (23).

\section{Results}

Of 533 participants, $184(34.5 \%)$ were females and $348(65.2 \%)$ were males., and $1(0.2 \%)$ prefer not to say (Table 1$)$. The average age of the participants was 43.46 (range $=20$ to 69 years). $75.4 \%(n=402)$ of participants were single. Most of the participants had secondary or further education, $41.8 \%$ ( $=223)$ and 43.7\% ( $n=233$ ) respectively. Most of the participants lived in independent accommodation $(73.5 \%, n=392) .46 .1 \%(n=246)$ of the participants lived alone. Many of the participants were unemployed $(70.3 \%, n=375)$, with only $10 \%(n=57)$ in voluntary employment and $9.1 \%(n=49)$ in full- or part-time employment. The majority of participants were receiving state benefits $(88.7 \%, n=473)$.

The main psychiatric diagnosis was schizophrenia $68.5 \%(n=250)$, followed by schizoaffective disorder $15.8 \%(n=81)$ and brief psychotic disorder $2.6 \%(n=$ 13). Most of the participants were White British 63.7\% $(n=340), 12.9 \%(n=69)$ were Black/ Black British and $11.4 \%(n=61)$ were Asian/Asian British. Table 1 provides further details about the socio-demographic characteristics of the sample.

Table 2 provides the descriptive statistics of quality of life, leisure activities and a number of variables such as sport activities.

The mean quality of life score (on a scale of 1 to 7 ) was 4.98. On average, participants attended 2.42 leisure activities in the last week. The quality of life scores increased slightly with the number of leisure activities participants had attended. For example, from zero to 1 leisure activity, the quality of life mean score increased from 4.62 to 4.89 , and then with 2 leisure activities, the quality of life mean score increased to 5.03 . From 4 to 5 leisure activities, the quality of life mean score increased from 5.15 to 5.35 (Table 2).

The leisure activities included visit to the Museum, Entertainment (Club), Event (Sport or Music), Outdoor Trips, Library, Community Centre, Shopping, Cinema, Religious Activities, Been Visited by Friends, Visited Friends, and Been out to Eat.

The most frequent leisure activities were "going out to eat" or "shopping". On average, participants had 2.11 social contacts in the last week and on average participants attended 0.76 sports activities. Of 535 participants, $48 \%(\mathrm{~N}=257)$ did not take part in any sports activities.

\section{Multiple regression analysis}

Table 3 presents the relationship between attendance in leisure activities and the quality of life of people with psychosis.

Univariable tests

The results of univariable linear regression showed a significant relationship between attendance in leisure activities and quality of life; $b=.0973081$, Standard Error $=.0342267, z=2.84 p=0.005,95 \% \mathrm{Cl}[.0300239$ to .1645923$]$. 
In a further multivariable model, the association between attendance in leisure activities and quality of life remained significant; $b=0.086$, Standard Error $=$ $0.035, z=2.43, p=0.016,95 \% \mathrm{Cl}[0.016$ to 0.156$]$ (see Table 3 ). Before to add these confounders into the multivariable model, we tested whether an association at the level of $p<0.10$ was found in univariable model.

We tested the gender difference by conducting a multivariable model of each sample. For Males: the association between attendance in leisure activities and quality of life is significantly positive; $b=0.132$, Standard Error $=0.041, z=3.18, p=0.002,95 \% \mathrm{Cl}[0.050$ to 0.213$]$. For females: No association between attendance in leisure activities and quality of life; $b=0.015$, Std Err $=0.069, z=0.23, p=0.821,95 \% \mathrm{Cl}[-0.121$ to 0.152$]$ (see Table 4).

\section{Discussion}

This study investigated whether attendance in leisure activities is associated with the quality of life of people with psychosis in England. The study found that attendance in leisure activities is positively associated with the quality of life of people with psychosis. On average, participants attended two leisure activities in the last week and their quality of life increased slightly with the number of leisure activities attended.

Our findings suggest that, while people with psychosis have usually specific difficulties in engaging with social activities (24-26), weekly leisure activities such as going out for shopping or visiting a museum are associated with a higher quality of life.

Previous studies which report a positive link between quality of life and leisure activities have suggested that this could be because leisure activities can increase individuals' perception of spending their time effectively (3). This may suggest that interventions which support people to engage in leisure activities should be used with people with psychosis. However, due to the cross-sectional nature of the data it is not possible to determine the causality of this association.

Our findings are in line with previous studies suggesting that participation in leisure activities are positively associated with the quality of life of vulnerable people including older people (6), and people with common mental health conditions (7-9).

Gender difference in mental health

This study found that both males et females participated in leisure activities. However, the link between leisure activities and quality of life was much stronger amongst males and non-significant amongst females. Our findings are in line with previous studies suggesting that both males and females with severe mental health conditions can be involved in leisure activities (10). Nevertheless, when it comes to the impact leisure activities have on their quality of life, males seem to benefit more from leisure activities than women because their participation in leisure activities was significantly and positively associated with their quality of life. Previous studies looking at the association between leisure time physical activity in adolescence and poor mental health in early adulthood found that males are likely to benefit from leisure time physical activity than females (9). These findings need to be treated with caution because of the unbalanced sample between males and females and the small sample size of females' participants.

Strengths and limitations

This study has several strengths. First, this is the first multi-site cross-sectional study investigating the link between the attendance in leisure activities and the quality of life of people with psychosis in England.

Second, this study recruited a large sample across several mental health providers covering a variety of urban and rural areas in England. It may inform researchers who are developing the implementation of psycho-social interventions for people with psychosis $(11,27)$.

Nevertheless, it is important to recognise some limitations. First, participants were identified by clinicians or clinical study officers and asked for their agreement to take part in this research study. It is possible that people who agreed to participate were more comfortable with engagement in leisure activities compared to those who declined to take part in this study. Second, of 533 participants, 184 (34.5\%) were females and 348 (65.2\%) were males. This may explain why the attendance in leisure activities was associated with higher quality of life amongst males' participants and not significant amongst females. Third, this is a cross-sectional study looking at the association between attendance in leisure activities and the quality of life of people with psychosis. To establish a causal association, longitudinal or intervention studies are required to explore whether there is a change in quality of life of people with psychosis resulting from engagement in leisure activities. It is possible that those with a higher quality of life feel better in general and are more able to engage in leisure activities.

\section{Conclusion}

Attendance in leisure activities is linked with higher quality of life. We find a gender difference between males and females. The association between attendance in leisure activities and quality of life is significantly positive amongst males and not significant amongst females. Further research is needed to determine whether interventions to increase attendance in leisure activities should be tried in people with psychosis.

\section{Declarations}

Ethics approval and consent to participate 
The West Midlands - Solihull Research Ethics Committee (17/WM/0191) approved the study, protocol, and informed consent forms. All participants were given the information sheet about the survey and written informed consent was obtained from all participants.

Consent for publication

"Not applicable"

Availability of data and materials

The datasets used and/or analysed during the current study are available from the corresponding author on reasonable request.

Competing interests

All authors declare no competing interests.

Funding

This study has been funded by the National Institute for Health Research (NIHR) under the Programme Grants for Applied Research programme [RP-PG-061520009].

Role of the funding source

The funder National Institute for Health Research had no role in study design, data collection, data analysis, data interpretation, or writing of the report. The corresponding author had full access to all the data in the study and had final responsibility for the decision to submit for publication.

Authors' contributions

$\mathrm{KN}$ carried out the literature review and the selection of the references. DG led the study protocol development. DG and MW supervised data collection across the study sites.

KN prepared the data for the analysis. KN did the data analysis with advice from DG, MW who also supported KN in the interpretation of the results. PX and AC carried out the final check from the introduction to results and discussion. KN takes responsibility for the integrity of the data and the accuracy of the data analysis. All authors reviewed the manuscript and contributed to its final draft.

Acknowledgements

We would like to thank the funder of this research "the National Institute for Health Research (NIHR) under the Programme Grants for Applied Research programme".

We would like to gratefully acknowledge the vital help and support from clinicians and clinical study officers at all NHS Trusts involved, who helped the local promotion of this study and the identification of participants.

Also, we would like to thank all participants who willingly agreed to take part in this study.

\section{References}

1. Lee H, Heo S. Benefits of leisure activities for the quality of life of older South Korean adults. Leisure Studies.

2. OECD. Special focus: measuring leisure in OECD countries. In OECD Society at a Glance. OECD Social Indicators; 2009.

3. Goodman WK, Geiger AM, Wolf JM. Leisure activities are linked to mental health benefits by providing time structure: comparing employed, unemployed and homemakers. J Epidemiol Community Health. 2017;71(1):4-11.

4. Aughterson H, Baxter L, Fancourt D. Social prescribing for individuals with mental health problems: a qualitative study of barriers and enablers experienced by general practitioners. Bmc Family Practice. 2020;21(1).

5. Tyrer P, Boardman J. Refining social prescribing in the UK. Lancet Psychiatry. 2020;7(10):831-2.

6. Lee JH, Park SH. Leisure Activity Participation as Predictor of Quality of Life in Korean Urban-dwelling Elderly. Occupational Therapy International. 2014;21(3):124-32.

7. Carter T, Morres ID, Meade O, Callaghan P. The Effect of Exercise on Depressive Symptoms in Adolescents: A Systematic Review and Meta-Analysis. J Am Acad Child Adolesc Psychiatry. 2016;55(7):580-90.

8. Kim J, Han A. The impact of leisure time physical activity on mental health and health perception among people with cancer. Health Promotion Perspectives. 2020;10(2):116-22.

9. Poulsen $\mathrm{PH}$, Biering K, Andersen JH. The association between leisure time physical activity in adolescence and poor mental health in early adulthood: a prospective cohort study. Bmc Public Health. 2016;16.

10. Takeda F, Noguchi H, Monma T, Tamiya N. How Possibly Do Leisure and Social Activities Impact Mental Health of Middle-Aged Adults in Japan?: An Evidence from a National Longitudinal Survey. Plos One. 2015;10(10). 
11. Webber M, Fendt-Newlin M. A review of social participation interventions for people with mental health problems. Soc Psychiatry Psychiatr Epidemiol. 2017;52(4):369-80.

12. Mgonja JT. Leisure and recreation in non-western societies: critical perspectives and implications for future research. World Leisure Journal. 2020;62(3):261-71.

13. Veal AJ. Definitions of Leisure and Recreation. Australian Journal of Leisure and Recreation; 1992. p. 44-8.

14. Hein V, Koka A, Kalajas-Tilga H, Tilga H, Raudsepp L. The effect of grit on leisure time physical activity. An application of the Theory of Planned Behaviour. Baltic Journal of Health Physical Activity. 2020;12(1):78-85.

15. Killaspy H, White S, Lalvani N, Berg R, Thachil A, Kallumpuram S, et al. The impact of psychosis on social inclusion and associated factors. Int $\mathrm{J}$ Soc Psychiatry. 2014;60(2):148-54.

16. Harvey CA, Jeffreys SE, McNaught AS, Blizard RA, King MB. The camden schizophrenia surveys III: Five-year outcome of a sample of individuals from a prevalence survey and the importance of social relationships. Int J Soc Psychiatry. 2007;53(4):340-56.

17. Kasanova Z, Oorschot M, Myin-Gerrneys I. Social anhedonia and asociality in psychosis revisited. An experience sampling study. Psychiatry Res. 2018;270:375-81.

18. Hansen CF, Torgalsboen AK, Melle I, Bell MD. Passive/Apathetic Social Withdrawal and Active Social Avoidance in Schizophrenia Difference in Underlying Psychological Processes. Journal of Nervous Mental Disease. 2009;197(4):274-7.

19. Lader D, Short S, Gershuny J. The time use survey, 2005. London: The national Amendment, Office for National Statistics.; 2006.

20. Bjorkman T, Svensson B. Quality of life in people with severe mental illness. Reliability and validity of the Manchester Short Assessment of Quality of Life (MANSA). Nord J Psychiatry. 2005;59(4):302-6.

21. Petkari E, Giacco D, Priebe S. Factorial structure of the Manchester Short Assessment of Quality of Life in patients with schizophrenia-spectrum disorders. Qual Life Res. 2020;29(3):833-41.

22. Priebe S, Huxley P, Knight S, Evans S. Application and results of the Manchester Short Assessment of Quality of Life (MANSA). Int J Soc Psychiatry. 1999;45(1):7-12.

23. Khojasteh J. Statistical Analysis of Questionnaires: A Unified Approach Based on R and Stata. Structural Equation Modeling-a Multidisciplinary Journal. 2019;26(6):986-7.

24. Giacco D, Palumbo C, Strappelli N, Catapano F, Priebe S. Social contacts and loneliness in people with psychotic and mood disorders. Compr Psychiatry. 2016;66:59-66.

25. Lloyd-Evans B, Frerichs J, Stefanidou T, Bone J, Pinfold V, Lewis G, et al. The Community Navigator Study: Results from a feasibility randomised controlled trial of a programme to reduce loneliness for people with complex anxiety or depression. Plos One. 2020;15(5).

26. Webber M, Reidy H, Ansari D, Stevens M, Morris D. Enhancing social networks: a qualitative study of health and social care practice in UK mental health services. Health Social Care in the Community. 2015;23(2):180-9.

27. Kimberley A, Neelam L, Stefan P. Can mental health interventions change social networks? A systematic review. BMC Psychiatry. 2015;15:297.

\section{Tables}

Table 1. Descriptive statistics: socio-demographic information 


\begin{tabular}{|c|c|}
\hline Variables & $\mathrm{N}=533(\%)$ \\
\hline \multicolumn{2}{|l|}{ Gender } \\
\hline Female & $184(34.5 \%)$ \\
\hline Male & $348(65.2 \%)$ \\
\hline Prefer not to say & $1(0.2 \%)$ \\
\hline \multicolumn{2}{|l|}{ Marital status } \\
\hline Single & $402(75.4 \%)$ \\
\hline Married & $65(12.2 \%)$ \\
\hline Co-habiting / civil partnership & $13(2.4 \%)$ \\
\hline Separated & $6(1.1 \%)$ \\
\hline Divorced & $37(6.9 \%)$ \\
\hline Widow/Widower & $7(1.3 \%)$ \\
\hline Not known/Missing & $3(0.5 \%)$ \\
\hline \multicolumn{2}{|l|}{ Education } \\
\hline Primary Education or less & $40(7.5 \%)$ \\
\hline Secondary Education & $223(41.8 \%)$ \\
\hline Tertiary / Further Education & $233(43.7 \%)$ \\
\hline Other general Education & $24(4.5 \%)$ \\
\hline Unknown/Missing & $13(2.4 \%)$ \\
\hline \multicolumn{2}{|l|}{ Accommodation } \\
\hline Independent accommodation & $392(73.5 \%)$ \\
\hline Supported accommodation & $114(21.3 \%)$ \\
\hline Homeless/Roofless & $6(1.1 \%)$ \\
\hline Other accommodation & $19(3.5 \%)$ \\
\hline \multicolumn{2}{|l|}{ Living condition } \\
\hline Living alone & $246(46.1 \%)$ \\
\hline Living with a partner or family & $186(34.9 \%)$ \\
\hline Living with friend(s) & $8(1.5 \%)$ \\
\hline Living in shared accommodation & $90(16.8 \%)$ \\
\hline \multicolumn{2}{|l|}{ Employment } \\
\hline Full-time paid or self-employed & $20(3.7 \%)$ \\
\hline Part-time paid or self-employed & $29(5.4 \%)$ \\
\hline Voluntary employ. & $57(10.6 \%)$ \\
\hline Unemployment & $375(70.3 \%)$ \\
\hline Student & $19(3.5 \%)$ \\
\hline Housewife/husband & $5(0.9 \%)$ \\
\hline Retired & $8(1.6 \%)$ \\
\hline Other & $10(1.8 \%)$ \\
\hline \multicolumn{2}{|l|}{ State benefits } \\
\hline No & $43(8.0 \%)$ \\
\hline Yes & $473(88.7)$ \\
\hline \multicolumn{2}{|l|}{ Main psychiatric diagnosis } \\
\hline Schizophrenia & $250(68.5 \%)$ \\
\hline Schizotypal disorder & $3(0.6 \%)$ \\
\hline Delusional disorder & $12(2.3 \%)$ \\
\hline
\end{tabular}

Page $8 / 10$ 


\begin{tabular}{|ll|} 
Brief Psychotic Disorder & $13(2.6 \%)$ \\
Schizoaffective disorder & $81(15.8 \%)$ \\
Psychosis NOS & $31(6.1 \%)$ \\
\hline Ethnicity & \\
White British & $340(63.7 \%)$ \\
Black/ Black British & $69(12.9 \%)$ \\
Asian/Asian British & $61(11.4)$ \\
\hline
\end{tabular}

Table 2: Descriptive statistics of quality of life, leisure activities, and sport activities.

\begin{tabular}{|c|c|c|c|c|c|}
\hline & $\mathrm{N}$ & Mean & Std. Err. & {$[95 \%$ Conf. } & Interval] \\
\hline Quality of life MANSA & 407 & 4.98 & .05 & 4.88 & 5.08 \\
\hline Leisure activities & 535 & 2.42 & .06 & 2.29 & 2.54 \\
\hline Sport activities & 535 & .76 & .04 & .68 & .84 \\
\hline Quality of life MANSA with no leisure activity & 40 & 4.67 & .17 & 4.31 & 5.02 \\
\hline Quality of life MANSA with 1 leisure activity & 59 & 4.89 & .13 & 4.62 & 5.15 \\
\hline Quality of life MANSA with 2 leisure activities & 114 & 5.03 & .08 & 4.86 & 5.20 \\
\hline Quality of life MANSA with 3 leisure activities & 88 & 4.82 & .10 & 4.61 & 5.03 \\
\hline Quality of life MANSA with 4 leisure activities & 62 & 5.15 & .12 & 4.91 & 5.40 \\
\hline Quality of life MANSA with 5 leisure activities & 38 & 5.35 & .17 & 4.98 & 5.71 \\
\hline Quality of life MANSA with 6 leisure activities & 6 & 5.22 & .83 & 3.07 & 7.37 \\
\hline Quality of life MANSA by leisure activity & 535 & Mean & Std. Err. & [95\% Conf. & Interval] \\
\hline Out to eat & 250 & 5.02 & .06 & 4.90 & 5.15 \\
\hline Entertainment & 23 & 5.12 & .18 & 4.73 & 5.51 \\
\hline Out for an Event & 26 & 5.32 & .19 & 4.91 & 5.72 \\
\hline Visiting Friends & 140 & 4.99 & 0.07 & 4.83 & 5.14 \\
\hline Going to the Library & 59 & 4.84 & 0.16 & 4.51 & 5.17 \\
\hline Visiting the Museum & 21 & 5.39 & 0.22 & 4.92 & 5.87 \\
\hline Outdoor trips & 64 & 5.07 & .14 & 4.79 & 5.36 \\
\hline Attending a religious activity & 47 & 5.02 & 0.13 & 4.74 & 5.30 \\
\hline Been to a Shopping centre & 151 & 5.21 & 0.08 & 5.04 & 5.37 \\
\hline Visited by friends & 105 & 5.10 & 0.10 & 4.90 & 5.31 \\
\hline Attending a community centre & 87 & 4.96 & 0.11 & 4.74 & 5.19 \\
\hline Year of Birth & 533 & 1974.54 & 10.92 & 1949 & 1998 \\
\hline
\end{tabular}

MANSA: Manchester Short Assessment of Quality of Life

SD: Standard Deviation

Table 3 Multiple regression analyses investigating the association between the attendance in leisure activities and quality of life.

Dependent variable: Quality of life 


\begin{tabular}{|llllllll|}
\hline Quality of life & Coef. b & Std. Err. & z & P value & [95\% C & l] \\
\hline Attendance in leisure activities & $.0835763^{* *}$ & .0355022 & 2.35 & 0.019 & .0137778 & .1533748 \\
\hline Marital status & & & & & & \\
\hline Education level & $-.0889578^{*}$ & .0429035 & -2.07 & 0.039 & -.1733076 & -.004608 \\
& & & & & & \\
\hline Sport activities & $-.119737 n s$ & .0715959 & -1.67 & 0.095 & -.2604969 & .021023 \\
\hline
\end{tabular}

P-value significant: $0.001 * \star * ; 0.01 * * ; 0.05^{\star}, \mathrm{ns}=$ non-significant

Table 4. Multiple regression analyses investigating the association between the attendance in leisure activities and quality of life.

Dependent variable: Quality of life

\begin{tabular}{|c|c|c|c|c|c|c|c|c|c|c|c|c|}
\hline & Males & & & & & & Females & & & & & \\
\hline $\begin{array}{l}\text { Quality of } \\
\text { life }\end{array}$ & Coef. b & Std. Err. & $z$ & Value & {$[95 \%$ C } & l] & Coef.b & Std.Err & $z$ & Pvalue & {$[95 \% \mathrm{C}$} & I] \\
\hline $\begin{array}{l}\text { Attendance } \\
\text { in leisure } \\
\text { activities }\end{array}$ & $.132042^{\star \star}$ & .0415172 & 3.18 & 0.002 & .0503052 & .2137797 & $.015633 \mathrm{~ns}$ & .0692967 & 0.23 & 0.822 & -.12163 & ك.152896 \\
\hline $\begin{array}{l}\text { Marital } \\
\text { status }\end{array}$ & $-.07519 \mathrm{~ns}$ & .0494866 & -1.52 & 0.130 & -.172619 & .0222341 & $-.097443 n s$ & .0865667 & -1.13 & 0.263 & -.268915 & .074029 \\
\hline $\begin{array}{l}\text { Education } \\
\text { level }\end{array}$ & $-.10387 n s$ & .0797097 & -1.30 & 0.194 & -.260802 & .0530553 & $-.162863 \mathrm{~ns}$ & .1505133 & -1.08 & 0.281 & -.461001 & .135274§ \\
\hline $\begin{array}{l}\text { Sport } \\
\text { activities }\end{array}$ & $.1195605^{\star}$ & .0602809 & 1.98 & 0.048 & .0008821 & .238239 & $.066357 \mathrm{~ns}$ & .1468573 & 0.45 & 0.652 & -.224539 & $.357252 C$ \\
\hline
\end{tabular}

P-value significant: $0.001 * * * ; 0.01 * * ; 0.05^{*}, \mathrm{~ns}=$ non-significant 